\title{
Understanding African Americans' Views of the Trustworthiness of Physicians
}

\author{
Elizabeth A. Jacobs, MD, MPP, I Italia Rolle, RD, PhD, ${ }^{2}$ Carol Estwing Ferrans, RN, PhD, ${ }^{3}$ Eric E. \\ Whitaker, MD, MPH, ${ }^{4}$ Richard B. Warnecke, $P h D^{5}$ \\ 'John H. Stroger, Jr. Hospital of Cook County \& Rush University Medical Center, Chicago, IL, USA; ${ }^{2}$ National Center on Birth Defects \& \\ Developmental Disabilities, CDC, Atlanta, GA, USA; ${ }^{3}$ University of Illinois at Chicago College of Nursing, Chicago, IL, USA; ${ }^{4}$ llinois \\ Department of Public Health, Chicago, IL, USA; ${ }^{5}$ University of Illinois at Chicago School of Public Health Center for Population Health and \\ Health Disparities, Chicago, IL, USA.
}

\begin{abstract}
BACKGROUND: Many scholars have written about the historical underpinnings and likely consequences of African Americans distrust in health care, yet little research has been done to understand if and how this distrust affects African Americans' current views of the trustworthiness of physicians.
\end{abstract}

OBJECTIVE: To better understand what trust and distrust in physicians means to African Americans.

DESIGN: Focus-group study, using an open-ended discussion guide.

SETTING: Large public hospital and community organization in Chicago, IL.

PATIENTS: Convenience sample of African-American adult men and women.

MEASUREMENTS: Each focus group was systematically coded using grounded theory analysis. The research team then identified themes that commonly arose across the 9 focus groups.

RESULTS: Participants indicated that trust is determined by the interpersonal and technical competence of physicians. Contributing factors to distrust in physicians include a lack of interpersonal and technical competence, perceived quest for profit and expectations of racism and experimentation during routine provision of health care. Trust appears to facilitate care-seeking behavior and promotes patient honesty and adherence. Distrust inhibits care-seeking, can result in a change in physician and may lead to nonadherence.

CONCLUSIONS: Unique factors contribute to trust and distrust in physicians among African-American patients. These factors should be considered in clinical practice to facilitate trust building and improve health care provided to African Americans.

KEY WORDS: trust; distrust; African Americans; physicians.

DOI: $10.1111 /$ j. 1525-1497.2006.00485.x

J GEN INTERN MED 2006; 21:642-647.

I nterpersonal trust between a physician and patient has been shown to be an important determinant of care. Greater interpersonal trust has been found to be a significant predictor of acceptance of recommended care,${ }^{1-4}$ satisfaction with care,$^{5-7}$ loyalty and satisfaction with the physician, ${ }^{4,8,9}$ selfreported health improvement, ${ }^{4,8,9}$ and willingness to give the physician control in the relationship. ${ }^{10}$

None of the authors have any conflicts of interest to declare. The research presented in this paper was supported by Cancer Prevention, Control, and Population Sciences Career Development Award \#5K07CA089421-03 from the National Cancer Institute. An earlier version of this work was presented at the Society of General Internal Medicine 25th Annual Meeting, Atlanta, GA, May 2 to 4, 2002 and the Academy for Health Services Research and Health Policy Annual Meeting, Washington, DC, June 23 to 25, 2002.

Address correspondence and requests for reprints to Dr. Jacobs: Collaborative Research Unit, 1900 West Polk Street, 16th floor, Chicago, IL 60612 (e-mail: ejacobs@rush.edu).
While most research on interpersonal trust has focused on Caucasian patients, views of the trustworthiness of health care are likely to differ for African Americans given the historical legacy of mistreatment at the hands of the medical profession, witness the Tuskegee syphilis experiment, and current health disparities. ${ }^{11-13}$ In multivariate analyses, Kao et al. ${ }^{9}$ found that African-American patients were less trusting of their physicians, regardless of payment method than were their Caucasian counterparts. Another study did not find differences by race. ${ }^{14}$ This lack of consistency may be due to the fact that these studies focused on trust and not distrust. Studies that have focused on distrust have shown significant differences between African Americans and Caucasians in their distrust of the motives of the medical profession in withdrawal of life-sustaining technology, pursuit of organ donation, research, and health care over all. ${ }^{12,15-22}$

The objective of this study was to better understand what trust and distrust in physicians mean to African Americans. We were interested in the determinants of trust and distrust in physicians, the relationship between trust and distrust and their impact on participants' care-seeking behavior. Because the goal of this study was to learn more about the meaning and importance of these constructs to African Americans, rather than to test a hypothesis, we chose a qualitative study design in which participants could use their own words and stories to describe their experiences of trust and distrust.

\section{METHODS}

Nine focus groups were conducted with a convenience sample of participants recruited from a public hospital clinic and a community advocacy organization in Chicago, IL $(n=66)$. We recruited participants from the waiting room of the hospital clinic and through job and other activities organized by the advocacy organization with the goal of involving participants with a range of experience with health care.

Five of the 9 groups were with African-American women $(n=32)$ and 4 were with African-American men $(n=34)$. All groups were homogeneous by gender. Females and males were recruited separately by gender-matched African-American research assistants. Female participants were African American and at least 40 years of age. Males were African American and at least 18 years of age. Participants were excluded if they did not self-identify as African American, did not meet the age requirements, were unable to consent because of mental or other impairments, or could not participate in one of the scheduled

Manuscript received June 20, 2005

Initial editorial decision February 16, 2006

Final acceptance March 6, 2006 
focus groups. Participants were provided with food and a $\$ 35$ incentive for their participation in the focus groups. The age inclusion criterion differed by gender group because the initial goal of the study was to examine trust issues in African-American women eligible for breast and cervical cancer screening. When the study was expanded to examine issues of trust and distrust in African Americans in general, we recruited younger men to ensure that we also obtained the views of a sample of younger African Americans. We did not conduct additional focus groups with younger women because an analysis comparing major themes in the men's groups with those of the women's groups indicated there were no major differences by gender or age. Similarly there were no differences in the themes identified from the hospital clinic groups when compared with the community advocacy groups. Both the Cook County Hospital and University of Illinois at Chicago Institutional Review Boards approved the research protocol and all research participants provided informed consent.

The focus groups were conducted at 2 sites: the University of Illinois Survey Research Laboratory and the Westside Health Authority, a community advocacy organization. Focus group discussions were moderated and observed by trained, experienced, and gender-matched African-American professional moderators. The research assistants were also African American. Semi-structured focus questions were derived from a literature review and our research hypotheses (see Appendix A). They were designed to promote discussion about determinants of participants' trust and distrust in physicians and how trust and distrust shaped participant's health care decision making. The focus group moderators were also instructed to probe for how experiences of differential treatment and perceptions of experimentation in health care affected trust. The focus group discussions were audiotaped and written notes were taken by an observer. The written notes were used to supplement the information gleaned through the audiotapes. To ensure that the transcripts accurately reflected the discussion that took place, they were reviewed by 2 members of the research team (E.J. and I.R.) who had observed the live focus groups. At the end of each group, participants completed demographic questions about their age, years of education, number of doctor visits in the previous year, and type of health insurance.

The focus group discussions were transcribed verbatim and imported into ATLAS.ti 4.2 software program. ATLAS ti is a tool for organizing the data and for qualitative coding of text data. We were guided by grounded theory in our analysis so as to be able to glean information from the focus group data rather than testing empirical assumptions or hypotheses. ${ }^{23}$ Seventeen initial codes were developed based on the interview guide. Forty-nine additional codes were added during the analysis as additional themes emerged. Two trained coders coded each transcript. Both had to agree on the final code definition and rules for its use before it was applied in coding. The 2 coders proposed new codes or refined old codes and after several iterations of transcript review, a final codebook was developed. All transcripts were coded using the final list of codes. We calculated a $\kappa$ statistic to establish intercoder reliability using codes from 2 transcripts and found the $\kappa$ to be 0.9 before the final coding of all transcripts. The query tool of ATLAS.ti provided quotations for each individual code.
Pattern themes, defined as concepts that occurred frequently across all 9 groups, were identified from the analysis of the coded text. We report the qualitative results by summarizing the overall themes that occurred across all groups and providing 1 or 2 representative and illustrative quotes of the themes. Space precludes presenting all informative quotes. The demographic data were analyzed by STATA 7 using Chisquare and $t$ tests for bivariate and continuous data, respectively.

\section{RESULTS \\ Demographic Characteristics}

Thirty-two women and 34 men participated in the study (Table 1). The mean age of the women participants was significantly older than that of the male participants $(P=.0005)$. The majority of participants had completed high school, but the men were significantly more likely to have entered college than the women $(P=.005)$. More than $80 \%$ all respondents had seen a doctor in the past year and there were no significant differences in the annual number of visits made by males or females. More than $60 \%$ of subjects in both groups had either private or federal insurance coverage. There were no significant gender differences in insurance status or type of insurance.

\section{Trust in Health Care Providers}

We explored participants' views about health care providers by asking questions about what made them trust doctors. In addition, we asked if there were certain characteristics of doctors such as race and ethnic background that made them more trusting of the physician. Common themes regarding trust in physicians were similar across gender. Participants indicated that they trusted physicians who demonstrated interpersonal and technical competence (Table 2).

Interpersonal Competence. Interpersonal competence included the common themes of physician caring and empathy, taking the time to listen, honesty, and keeping the patient's

Table 1. Demographic Characteristics of the Sample

\begin{tabular}{|c|c|c|c|}
\hline & Female & Male & $P$ \\
\hline$N$ & 32 & 34 & NS \\
\hline Age (mean \& range) (y) & 55 (40 to 73 ) & 43 (18 to 71$)$ & .0005 \\
\hline Education (\%) & & & .005 \\
\hline Middle school or less & 3.1 & 1.5 & \\
\hline Some high school & 31.3 & 6.1 & \\
\hline High school & 31.3 & 36.4 & \\
\hline Some college & 31.3 & 45.5 & \\
\hline $\begin{array}{l}\text { Completed college or } \\
\text { higher degree }\end{array}$ & 3.1 & 7.7 & \\
\hline $\begin{array}{l}\text { Visited a doctor in } \\
\text { past year (\%) }\end{array}$ & 94 & 85 & NS \\
\hline $\begin{array}{l}\text { Number of visits to } \\
\text { doctor (mean \& range) }\end{array}$ & 4.67 (0 to 26$)$ & $3.09(0$ to 12$)$ & NS \\
\hline Health care insurance & & & NS \\
\hline Private & 25.8 & 36.4 & \\
\hline $\begin{array}{l}\text { Federal (medicaid or } \\
\text { medicare) }\end{array}$ & 35.5 & 26.6 & \\
\hline Military & 0.00 & 4.7 & \\
\hline No insurance & 38.7 & 37.5 & \\
\hline
\end{tabular}

NS, not significant. 
Table 2. Determinants and Consequences of Tru st and Distrust in Physicians

\begin{tabular}{|c|c|c|}
\hline & Trust & Distrust \\
\hline Determinants & $\begin{array}{l}\text { Interpersonal competence } \\
\text { Technical competence }\end{array}$ & $\begin{array}{l}\text { Interpersonal incompetence } \\
\text { Technical incompetence } \\
\text { Foreign physicians } \\
\text { Focus on profit } \\
\text { Racism } \\
\text { Expectation of experimentation }\end{array}$ \\
\hline Consequences & $\begin{array}{l}\text { Facilitates care-seeking } \\
\text { Promotes patient honesty } \\
\text { Enhances adherence }\end{array}$ & $\begin{array}{l}\text { Inhibits care-seeking } \\
\text { Promotes nonadherence } \\
\text { Leads to changing provider }\end{array}$ \\
\hline
\end{tabular}

best interest at heart. The following quotes are representative of each of these themes.

[My doctor] was so gentle ... I just gained trust in her through her conversation and her care that it felt to me that she just really cared about my problem and my pain that I had experienced and everything like that. And she gave me a guarantee almost, that I wouldn't go through those pains again. And to me, I just learned to trust her and seem like to me, she was the one that I looked to that really cared about me. (Male participant)

[Doctors should] be able to communicate and to have a good bedside manner. Take that extra maybe five or ten minutes. I may not mean an awful lot [to the doctor (referred to as you)]. Just show me that you are concerned. You know you don't have to sit in the room with me for twenty hours. Make me feel comfortable because this is my life and I want to trust. (Female participant)

Just be honest with the patient. (Male participant)

I think trust is important because when the doctor is going to perform a test or something you want to make sure that he has your best interest in mind first of all and not just doing things ... (Female participant)

Technical Competence. Technical competence was also a key aspect of trust. Participants commonly expressed trust in physicians that they viewed as technically competent when they made the right diagnosis, gave the appropriate treatment, and provided the correct follow-up care. As this participant commented:

I've got to see him. What he's doing to me. Am I getting better? All of these things that play into my recovery is what builds trust. I can sit here and talk to a physician and get all the answers that I want. But are they right? Are they making me well? You can pat me on the back or you can sit there and hold my hand but is this what is making me well? (Male participant)

\section{Distrust in Health care Providers}

More themes emerged around factors influencing distrust in physicians, including provision of interpersonally and technically incompetent care, difficulty communicating with foreign physicians, provider focus on profit, experiences of racism and expectations of experimentation (Table 2). The predominant themes were the same for men and women.

Interpersonal and Technical Incompetence. Physicians who were interpersonally incompetent were described as follows:

Because you going to know in the first 30 seconds, 'Oh, he's a jerk.' Some of them even won't say 'Hi.' They just start doing things. (Male participant)

Many participants described experiences where the physicians barely spoke to them and did not examine them but immediately took out a prescription pad and wrote a prescription. As one participant stated:

They will honestly write you a prescription and not even have looked at you. (Female participant)

Physician Characteristics. Participants did not trust "foreign doctors" because of language and cultural differences. The following comments are typical responses to questions about whether the nationality of the physician made a difference: It's a big problem when [the doctor] don't understand you and you don't understand nothing he's saying, cause he's telling you to take these [medicines] (Male participant)

I have something with Asian doctors ... because of the language barrier and the culture barrier, I do not like them. (Female participant)

In contrast, the majority of respondents indicated that the race of the physician did not matter. As these participants reflected:

It's mostly the character of the person. It's not really the color. (Male participant)

I have had both Black and White doctors and I really have never had a bad experience. (Female participant)

Greed, Racism, and Experimentation. Participants often described how physicians focused on profit, rather than their care. As one participant stated:

I really don't trust the doctors that they really care about me because you know if you don't have insurance, if they don't see where they can get paid, they are really not interested in you.

(Female participant)

Focus group participants frequently mentioned an absence of trust in doctors who were perceived to treat patients' differently based on their race. One representative response to the question, "Do you think that if a white person goes in and seeks health care that it is different than if a black person does?" was:

I would think so ... The tone of voice, their whole demeanor changes to me. They change when they treat somebody white as opposed to you. They look at me and everything changes. They want to make sure they [referring to the white patient] are ok. (Female participant)

Participants also spoke about how experimentation and beliefs about experimentation in the health care setting affected their views of the trustworthiness of physicians.

As one female respondent said:

Over my period of time dealing with the medical field, I know that you do need a hell of a lot of trust in the physicians or the medical field and the institutions. But I don't know how most people are, but it reminds me of the Tuskegee Institute where they messed around and they made the brothers have the disease instead of 
treating them they just wanted to see how it was going to affect them. So maybe sometimes you go instead of getting treated they just want to see what its going to do to you and they'll try this and try that and they may give you a sugar pill. Because its not like they haven't seen anyone dead before so the only time they get affected [by dead people] is when its personal. So that's why a lot of people have mistrust.

When asked if they or anyone close to them believed they had been experimented on, participants described situations that occurred in the process of providing medical care. As one male participant described:

My [friend's] wife was experimented on like that from a doctor at the hospital ... and this doctor kept giving her medicine, medicine, and medicine and she went into a coma. And they were treating her for the wrong thing. And we brought her to the County after she came out of the coma. Then they said she had AIDS. But she didn't, she had lupus, plus she had leukemia. And this medicine that the doctor was treating her with is what put her into a coma. And so, you got to be careful. They will experiment. (Male participant)

The content of these responses indicates how the concern or belief that they were being experimented on influenced the interpretation of events that other patients might view as incompetence or even a mistake.

\section{Consequences of Trust and Distrust in Relationship to Receipt of Health care}

Respondents indicated that trust and distrust in physicians influenced their health care seeking behavior (Table 2). Trusting physician relationships were important to decision making about seeking care and following treatment recommendations and the patient's openness and honesty with the physician. As these 3 respondents said:

I feel that trust is important because if I trust a physician then whenever I have another condition I will feel free to go back to that physician instead of just, you know, sitting at home wondering or whatever. I feel comfortable going back to that physician to find out what is going on with me ... (Female participant)

I just have to agree with what everyone else has said especially about learning how to trust your doctor so you can be more open with him. (Female participant)

You have to trust the physician in order to answer questions free about your health and problems you are having. If you don't trust them you are going to hide things and hold things back. So that's what makes it a first priority. Trusting the doctor, cause if you don't trust them you are also not going to believe half of what he is telling you. (Male participant)

Respondents indicated that distrust in physicians often led them to forgo care by refusing surgery or other treatment, withdrawing from care all together, or not seeking it in the first place. It also led some patients to change physicians.

I am one of those people and a lot of times it is basically about distrust. You know I am not going to believe first of all what they tell me. Even if I went two or three doctors you know. And I also feel that too if I had the tumor again and I didn't want to get operated on it is not going to do but put much more worry on me. And that causes pain alone. (Female participant)

\section{DISCUSSION AND CONCLUSIONS}

The African Americans in our sample revealed that trust and distrust in physicians are complex constructs. While interpersonal and technical competence drive African Americans trust in physicians, distrust is more complex and arises out of more than incompetence. The participants in our study indicated that perceptions of physician greed and racism and expectations of experimentation in routine medical care contributed to their distrust of physicians. Not surprisingly, distrust negatively relates directly to the acceptance of and willingness to seek health care.

Our study is one of the few that has focused on understanding trust and distrust in physicians from an AfricanAmerican perspective. There have been a number of studies that have focused on trust in mixed populations, ${ }^{4,8,9,24,25}$ distrust of research as a barrier to research participation among African Americans ${ }^{12,15-18}$ and the relationship between trust or distrust and participation and satisfaction with medical care among African-American patients. ${ }^{19-22,26,27}$ Our findings add to this literature by highlighting factors that specifically contribute to distrust and trust of physicians among African Americans.

Our findings support common conceptual models of trust in physicians in the theoretical literature. ${ }^{10,14,28,29}$ Similar findings have also been documented in other qualitative studies. ${ }^{24,30,31}$ The participants in our study were very similar to other populations in describing physician trust as arising from their belief and experience with technical and interpersonal competence as demonstrated by compassion, reliability and dependability, communication skills and evidence that the best interests of the patient were at the forefront of physician-patient interactions.

What caused the African-American participants in our sample to distrust health care providers was different, and disturbing. Experiences and expectations of racism and financial discrimination by physicians were reported in all focus groups. The Institute of Medicine Report recently identified discrimination by physicians and health care systems as an important factor in contributing to health care disparities. ${ }^{32}$ Our findings suggest that an expectation of discrimination may also contribute to disparities. As participants in the groups indicated an expectation of discrimination can lead to distrust and distrust and, in turn, can lead to avoidance of care. This is not to blame African Americans for health care disparities but rather to highlight the fact that even when discrimination is not a conscious or unconscious intent expectations likely have an impact and need to be addressed.

Another disconcerting finding was the frequency with which focus group participants said that they expected to be experimented on in the course of routine medical care. Many participants perceived events that others would see as routine or incompetent medical care as experimentation and attributed this expectation to their knowledge of the Tuskegee Syphilis Study, whether or not they could identify the study by name. This was true for both the young and older participants. While there have been a number of studies on how Tuskegee and fear of experimentation affect African Americans' participation in research, ${ }^{12,15-18}$ little work has focussed on the interpretation of these experiences and how it affects willingness to seek and accept routine medical care. Participants also indicated that it is both the legacy of Tuskegee and also the reinforcement of their expectations of mistreatment in the present day that contribute to their distrust. This connection of the past and present to health behavior is worth further exploration as a possible source of health disparities. 
Receipt of substandard health care is an additional contributor to distrust among the participants in our sample. Experiences of improper evaluation and inadequate treatment were voiced with some frequency. The participants who described these circumstances learned to seek care elsewhere or not at all.

Surprisingly, the majority of respondents indicated that physician race did not influence their trust. What did matter was whether physicians could communicate across language and cultural barriers. This finding differs from previous research that has shown racial concordance between a patient and their physician to have a positive impact on satisfaction and health care utilization. ${ }^{33-35}$ Our findings may be different because racial concordance is a stronger determinant of satisfaction than trust, because participants were uncomfortable expressing a racial preference in a group discussion, or because patient's preference for physician race is unconscious.

This study has several limitations. This was a qualitative study involving 66 participants. As a result, the findings may not be generalizable. They serve mainly to raise important questions for further investigation. In addition, there were differences in mean age and education between the males and females in the sample. The fact that the themes that emerged in the study were no different between the men's and women's groups suggests that neither gender, age, nor educational status is a strong determinant of trust and distrust in physicians and among the participants in our study. Clearly, this needs to be explored in greater detail in larger studies. Our study participants were recruited from a public hospital and community setting in a large, urban Midwestern city. Most of the participants had had contact with the health care system in the past 12 months. Participants from different settings and with more diverse socioeconomic background and less health care exposure might have different views about trust and distrust in health care. Finally, we did not conduct a comparison between African Americans and other populations. Nevertheless, our findings regarding experimentation and racism are quite different from those in other studies focusing on trust in white participants, indicating that these factors are much more common in African Americans.

Despite its limitations, our research reveals potentially important issues that need to be addressed by researchers and clinicians interested in improving the trustworthiness of care provided to African-American patients. The matter of trust and distrust in health care needs to be studied in larger, more representative samples that include other health care providers in addition to physicians. In the meantime, health care providers can use the information from this study to think about how they might prevent distrust and build trust with their AfricanAmerican patients. Awareness of how some of commonly used language such as "Let's try this medicine" and behaviors like hurrying through an exam can raise the specter of experimentation or discrimination, a situation that is easy to correct by using more direct language such as "This medication works well for my patients with this problem." Health care providers must work to understand and earn the trust of their AfricanAmerican patients and avoid encouraging distrust.

We would thank our focus group leaders, Rise Jones, PhD, and Waldo Johnson, PhD, and Giselle Corbie-Smith, MD, for her thoughtful review of this manuscript.

\section{REFERENCES}

1. Ayanian JZ, Cleary PD, Weissman JS, Epstein AM. The effect of patients' preferences on racial differences in access to renal transplantation. N Engl J Med. 1999;341:1661-9.

2. Connelly JE, Campbell C. Patients who refuse treatment in medical offices. Arch Intern Med. 1987;147:1829-33.

3. Mostashari F, Riley E, Selwyn PA, Altice FL. Acceptance and adherence with antiretroviral therapy among HIV-infected women in a correctional facility. J Acquir Immune Def Syndr Hum Retroviol. 1998; 18:341-8.

4. Safran DG, Taira DA, Rogers WH, Kosinski M, Ware JE, Tarlov AR. Linking primary care performance to outcomes of care. J Fam Pract. 1998;47:213-20.

5. Keating NL, Green DC, Kao AC, Gazmararian JA, Wu VY, Cleary PD. How are patients specific ambulatory care experiences related to trust, satisfaction, and considering changing physicians. J Gen Intern Med. 2002;17:29-39.

6. Safran DG, Montgomery JE, Chang H, Murphy J, Rogers WH. Switching doctors: predictors of voluntary disenrollment from a primary physician's practice. J Fam Pract. 2001;50:130-6.

7. Thom DH, Bloch DA, Segal ES. An intervention to increase patients trust in their physicians: Stanford Trust Study Group. Acad Med. 1999;74:195-8.

8. Kao AC, Green DC, Zaslavsky AM, Koplan JP, Cleary PD. The relationship between method of physician payment and patient trust. JAMA. 1998;280:1708-14.

9. Kao AC, Green DC, Davis NA, Koplan JP, Cleary PD. Patients' trust in their physicians: effects of choice, continuity, and payment method. J Gen Intern Med. 1998;13:681-6.

10. Anderson LA, Dedrick RF. Development of the trust in physician scale: a measure to assess interpersonal trust in patient-physician relationships. Psychol Rep. 1990;67(part 2):1091-100.

11. Gamble VN. A legacy of distrust: African Americans and medical research. Am J Prev Med. 1993;9(suppl. 6):35-8.

12. Gamble V. Under the shadow of Tuskegee: African Americans and health care. Am J Public Health. 1997;87:1773-8.

13. Peterson L. Racial differences in trust. Reaping what we have sown? Med Care. 2002;40:81-4.

14. Hall MA, Dugan E, Zheng B, Mishra AK. Trust in physicians and medical institutions: what is it, can it be measured, and does it matter? Milbank Q. 2001;79:613-39.

15. Blackhall LJ, Frank G, Murphy ST, Michel v, Palmer JM, Azen SP. Ethnicity and attitudes towards life sustaining technology. Soc Sci Med. 1999;48:1779-89.

16. Corbie-Smith G, Thomas SB St., George DM. Distrust, race, and research. Arch Intern Med. 2002;162:2458-60.

17. Corbie-Smith G, Thomas SB, Williams MV, Moody-Ayers S. Attitudes and beliefs of African Americans toward participation in medical research. J Gen Intern Med. 1999;14:537-46.

18. Freimuth VS, Guinn SC, Thomas SB, Cole G, Zook E, Duncan T. African Americans' views on research and the Tuskegee Syphilis Study. Soc Sci Med. 2001;52:797-808.

19. Kraukauer EL, Truog RD. Case study: mistrust, racism and end-of-life treatment. Hastings Cent Rep. 1997;27:23-5.

20. LaVeist TA, Nickerson KJ, Bowie JV. Attitudes about racism, medical mistrust, and satisfaction with care among African American and white cardiac patients. Med Care Res Rev. 2000;57(suppl 1):146-61.

21. Lillie-Blanton M, Brodie M, Rowland D, Altman D, McIntosh M. Race, ethnicity, and the health care system: public perceptions and experiences. Med Care Res Rev. 2000;57(suppl 1):218-35.

22. Plawecki HM, Plawecki PJ. Improving organ donation rates in the black community. J Holist Nurs. 1992;10:34-46.

23. Glaser B, Strauss A. The Discovery of Grounded Theory. New York: Hawthorne; 1967.

24. Thom DH, Campbell B. Patient-physician trust: an exploratory study. J Fam Pract. 1997;44:169-76.

25. Hall MA, Dugan E, Balkrishnan R, Bradley D. How disclosing HMO physician incentives affects trust. Health Aff (Millwood). 2002;21: 197-206.

26. Boulware LE, Ratner LE, Cooper LA, Sosa JA, LaVeist TA, Powe NR. Understanding disparities in donor behavior: race and gender differences in willingness to donate blood and cadaveric organs. Med Care. 2002;40:85-95.

27. Boulware LE, Ratner LE, Sosa JA, Cooper LA, LaVeist TA, Powe NR. Determinants of willingness to donate living related and cadaveric or- 
gans: identifying opportunities for intevention. Transplantation. 2002;73:1683-91.

28. Caterinicchio RP. Testing plausible path models of interpersonal trust in patient physician treatment relationships. Soc Sci Med. 1979;13A: 81-99.

29. Gilson L. Trust and the development of health care as a social institution. Soc Sci Med. 2003;56:1453-68.

30. Doescher MP, Saver BG, Franks P, Fiscella K. Racial and ethnic disparities in perceptions of physician style and trust. Arch Fam Med. 2000;9:1156-63.

31. Mechanic D, Meyer S. Concepts of trust among patients with serious illness. Soc Sci Med. 2000;51:657-68.

\section{Supplementary Material}

The following supplementary material is available for this article online

Appendix A: Focus Group Questions.
32. Smedley BD, Stith AY, Nelson AR, eds. Institute of Medicine. Unequal Treatment: Confronting Racial and Ethnic Disparities in Health Care. Washington, DC: The National Academies Press; 2003.

33. La Veist TA, Nuru-Jeter A, Jones KE. The association of doctor-patient race concordance with health services utilization. J Public Health Policy. 2003;24:324-7.

34. La Veist TA, Nuru-Jeter A. Is doctor-patient race concordance associated with greater satisfaction with care? $J$ Health Soc Behav. 2002;43:296-306; [PMID: 12467254].

35. Saha S, Komaromy M, Koepsell TD, Bindman AB. Patient-physician racial concordance and the perceived quality and use of health care. Arch Intern Med. 1999;159:997-1004. 